\title{
INFLUENCE OF DIFFERENT NATURAL FIBER-BASED COMPOSITES USE AS A FILLER FOR CRACKING IN NUCLEAR REACTOR BIOLOGICAL SHIELDS
}

\author{
Amal A. EL-SAWY,** \\ ${ }^{1}$ Nuclear and Radiological Safety Research Center, Egyptian Atomic Energy Authority, Cairo, Egypt
}

\begin{abstract}
The biological shield is very important in the nuclear power reactor, so it is necessary to study the effect of crack on it. This work aims to study fiber composites as a radiation shielding for various purposes associated with nuclear installations, as properly as a repairing mixture for developing cracks in the biological shields of a nuclear power reactor. In this study, the MCNP5 model of a pressurized water reactor (PWR) was used. Four different fiber composites of natural fiber $(F P)\left(\rho=\left(1.373 \mathrm{~g} / \mathrm{m}^{3}\right)\right.$, fiber with lead $(F P P b)\left(\rho=2.756 \mathrm{~g} / \mathrm{cm}^{3}\right)$, cement fiber $(C F)$ $\left(\rho=2.095 \mathrm{~g} / \mathrm{m}^{3}\right)$ and cement-fiber-magnetite $(C F M)\left(\rho=2.858 \mathrm{~g} / \mathrm{cm}^{3}\right)$ were used as the filler materials for cracking in the biological shield. The total mass attenuation coefficients $\mu_{m}$ for the studied composites have been calculated by the Win X-Com program of gamma-ray at an energy range from $0.15-20 \mathrm{MeV}$. Neutron and gamma-ray fluxes and dose rates were calculated through different distances of the reactor shields for different fiber composites. Total dose rates through biological shield without cracking and after cracking have been calculated. Radiation Protection Efficiency (RPE \%) for all samples at the outer surface of the biological shield was calculated. The results showed that by using fiber composites as a filler for cracking, the values of flux and dose rate for neutrons and gamma-rays have decreased. Also, FPPb is the best material for gamma-ray because it contains lead, which has a high atomic number. While CFM has the best material shield for neutron and gamma-ray in addition to magnetite and boron carbide the properties of CFM composite were improved. Max. value of RPE \% for FPPb was (43.1\%), then CFM (37.2\%), Fp (30.2\%) and CF (20.2\%). From these results, it can be concluded that plastic fiber composites were the best materials that can be used as a filler in the biological shield of nuclear power reactors.
\end{abstract}

Keywords: biological shields, fiber composites, MCNP coed, crack, dose reduction.

\section{Introduction}

A biological shield is an absorbing material placed around a reactor or radioactive source in a nuclear power station to reduce radiation to a safe level for humans. The effectiveness of a material as a biological shield is proportional to its scattering and absorption cross-section. [1]. Also, the biological shield wall was used to support the reactor vessel [2]. At the radiation facility this added shield will reduce the safety working area. Nowadays the low cost and more lightweight alternate materials for nuclear reactor shielding have been studied [3].

The main advantages of shielding material are the cost-effectiveness and enormous quantities of concrete [4]. But concrete material has some drawbacks such as cracks can happen after a long time of radiation exposure and it is difficult to transportation $[5,6]$. Also, the concrete structures of a biological shield are weakened by the influence of the temperature increase and exposure to radiation which lead to the temperature increase and also, effects on the mechanical, physical and radiation shielding properties. To repair concrete, it is necessary to select the correct 
repair product, because all products are not suitable for all purposes. An ideal product suitable for overall patching may not work well on small cracks. To repair the structures of concrete to their original strength, the formula is suggested as a repair mortar for developing cracks in the biological shields. The requirements of improved plastics will be satisfied by this mortar. Besides its effectiveness in radiation shielding for this application, it has high mechanical strength, adhesiveness, and physical properties [7].

Thermoplastic materials can be used to produce novel materials that can be provided as shielding. Additionally, their other benefits include durability, low production costs and good thermal and chemical stability. Polymeric materials provide good attenuation for neutron, it has been recommended that these materials could be suitable as shielding for gamma and X-ray by addition heavyweight metal. Recently, many researchers have studied the effect of the disperse fillers in Varity polymers which satisfies the requirements for radiation shielding [8].

Fiber composites are environmental, lightweight materials, robust, inexpensive, recyclable, maintainable and recyclable [9]. Repairing concrete cracks is not a realistic mission because cracks are not always visible [10,11]. Generally, fibers used in concrete material are glass, steel, synthetic and natural fibers [12,13]. Natural fiber composites have the responsibility to enhance the mechanical properties of plastics and also reduce the cost and weight of the resultant product [14].

The essential purpose for which include fibers in cement and concrete is to alter and enhance some properties of these materials for example tensile and flexural. Cement fused natural fiber composites have been divided into low-density and high-density products. Various searches was using cement with changed masses to prepare concrete with different densities for research and power reactors to reduce neutron and gamma-ray [15]. Boron carbide $\left(\mathrm{B}_{4} \mathrm{C}\right)$ is widely used as a shielding material, also alone or combined with other materials for radiation shielding. Cement-fiber (CF) and cement-fiber-magnetite (CFM) composites were a proper shield, for both neutrons and gamma-rays with appropriate densities [16,17].

The present study aims essentially to design a mathematical model of Korean APR1400 MWe nuclear power reactor as a pressurized water reactor (PWR) by MCNP-5 code with agricultural fiber and industrial plastic wastes, for preparing natural fiber (FP) $\left(\rho=\left(1.373 \mathrm{~g} / \mathrm{m}^{3}\right)\right.$, fiber with lead $(\mathrm{FPPb})\left(\rho=2.756 \mathrm{~g} / \mathrm{cm}^{3}\right)$, cement fiber $(\mathrm{CF})\left(\rho=2.095 \mathrm{~g} / \mathrm{m}^{3}\right)$ and cement-fibermagnetite (CFM) $\left(\rho=2.858 \mathrm{~g} / \mathrm{cm}^{3}\right)$ mixtures that can be shaped in a variety forms as filler materials for cracking of the biological shield in nuclear power reactors.

\section{Materials and Methods}

\section{Calculations of Gamma-Ray Attenuation Parameters Mass Attenuation Coefficient $\left(\mu_{m}\right)$}

One of the significant parameters to assess the shielding topographies of materials is mass attenuation coefficient $\left(\mu_{\mathrm{m}}\right)$. For photon interaction, it is a fundamental feature of a substance that represents interaction and shielding performance. At exact photon energy, the $\mu_{\mathrm{m}}$ of an element is found to be constant, whereas for a compound or mixture is determined according to the composition of the elements. The $\mu_{\mathrm{m}}$ is a factor that represents the degree of absorption or scattering of radiation absorption or scattering by a chemical species or substance at a specified wave-length per unit mass. The coefficient $\mu_{\mathrm{m}}\left(\mathrm{in} \mathrm{cm}^{2} \cdot \mathrm{g}^{-1}\right)$ is calculated by the dividing of linear attenuation coefficient $\mu$ by the density of the absorber material $\rho$ by Eq. 1 [18].

$$
\mu_{\mathrm{m}}=\frac{\mu}{\rho}
$$

where: $\mu_{\mathrm{m}}$ is a constant that defines the rate of energy loss by a photon beam as it traverses a medium. 


\section{Radiation Protection Efficiency (RPE\%)}

$\mathrm{RPE} \%$ value is a significant parameter to show shield efficiency $\%$ to protect against radiation and calculated by using the Eq. 2 [18].

$$
R P E \%=\left(1-\frac{I}{I o}\right) \times 100 \%
$$

where: $I_{0}$ is the incident beam to the detector from the gamma-ray source without any absorber. I is transmitted beam from the sample to the detector.

\section{Mont Carlo Coed (MCNP-5)}

MCNP-5 is a mathematical code that is used to answer a transport equation to analyze radiation interactions with matter $[19,20]$. Also, it is suited for solving complicated threedimensional, time-dependent problems and it can be used to duplicate theoretically a statistical process (i.e., the interaction of particles with matters), it is especially effective for complicated problems which cannot be described using deterministic approaches [21]. The transmission of neutrons, gamma rays, and linked transport are all covered by this code [22]. Nuclear procedures that may be happened at the point of radiation and detector interaction can be used in this model. Also, it may be used to expect the transport, collection of incident particles in different applications such as the walls of a nuclear power plant, particle accelerator designing, space investigation and also in medical physics [23].

\section{Materials Compositions}

In this work, the data were taken from the previous references [14]. Four different fiber composites materials of fiber-plastic (FP) $\left(\rho=1.373 \mathrm{~g} / \mathrm{cm}^{3}\right)$, fiber with lead (FPPb) $(\rho=2.756$ $\left.\mathrm{g} / \mathrm{cm}^{3}\right)$, cement-fiber $(\mathrm{CF})\left(\rho=2.095 \mathrm{~g} / \mathrm{cm}^{3}\right)$ and cement-fiber-magnetite (CFM) $\left(\rho=2.858 \mathrm{~g} / \mathrm{cm}^{3}\right)$ composites have been investigated. The investigate Samples of FP composites have been prepared from high-density polyethylene HDPE waste, sugar cane bagasse fiber (NF), Zn stearate and dioctylphythalate (DOP). Boron carbide (B4C) and Lead oxide (PbO) were added to the FPPb composites [14]. Also, CF and CFM composites were prepared from natural fiber, styrene butadiene rubber latex (SBR), Portland cement, boron carbide and magnetite $\left(\mathrm{Fe}_{3} \mathrm{O}_{4}\right)$. All chemical composition of these fiber composites was taken from literatrure [15]. The weight fraction compositions of the concerned composites are given in Table 1.

Table 1. Weight fractions of fiber composites used as radiation shielding [24]

\begin{tabular}{cccccc}
\hline Element & $\begin{array}{c}\text { Concrete } \\
\rho=2.3\left(\mathrm{~g} / \mathrm{cm}^{3}\right)\end{array}$ & $\begin{array}{c}\mathrm{FP} \\
\rho=1.373(\mathrm{~g} / \\
\left.\mathrm{cm}^{3}\right)\end{array}$ & $\begin{array}{c}\mathrm{FPPb} \\
\mathrm{r}=2.756(\mathrm{~g} / \\
\mathrm{cm})^{3}\end{array}$ & $\begin{array}{c}\mathrm{CF} \\
\rho=2.095\left(\mathrm{~g} / \mathrm{cm}^{3}\right)\end{array}$ & $\begin{array}{c}\mathrm{CFM} \\
\rho=2.858\left(\mathrm{~g} / \mathrm{cm}^{3}\right)\end{array}$ \\
\hline $\mathrm{H}$ & 0.0100 & 0.0860 & 0.0435 & 0.0284 & 0.0178 \\
$\mathrm{~B}$ & & & 0.1491 & & 0.0929 \\
$\mathrm{C}$ & & 0.5774 & 0.3237 & 0.1091 & 0.0945 \\
$\mathrm{O}$ & 0.5320 & 0.3333 & 0.1288 & 0.4323 & 0.3282 \\
$\mathrm{Zn}$ & & 0.0010 & 0.0008 & & \\
$\mathrm{~Pb}$ & & & 0.3537 & & \\
$\mathrm{Ca}$ & 0.0440 & & & 0.3162 & 0.1268 \\
$\mathrm{Mg}$ & & & & 0.00602 & 0.0050 \\
$\mathrm{Na}$ & 0.0290 & & & 0.0294 & 0.2742 \\
$\mathrm{Fe}$ & 0.0140 & & & 0.0644 & 0.0258 \\
$\mathrm{Si}$ & 0.3370 & & & 0.0043 & 0.0017 \\
$\mathrm{~S}$ & & & & 0.0151 & 0.0061 \\
$\mathrm{Al}$ & 0.0340 & & & & 0.0287 \\
$\mathrm{Ti}$ & & & & & 0.0016 \\
$\mathrm{Cr}$ & & & & & \\
\hline
\end{tabular}




\section{Theoretical Study}

\section{Reference Reactor}

In this work, the Korean reactor with 1400 MWe was selected as the reference reactor. This 4,060 $\mathrm{MW}_{\text {th }}$ evolutionary PWR combines a number of design improvements depending on the Korean Standard Nuclear Power Plant (KSNP) design and enhancements to fulfil the utility's requirements for improved safety and economic goals, as well as new licensing challenges such as severe accident mitigation [25].

\section{Simulation Model}

The present study is based on modelling of the Korean 1400 MWe nuclear power reactor using MCNP-5 code to simulate the crack which occurs in the biological shield due to the temperature increase and radiation exposure. This model analyzes the neutron and gamma-ray fluxes and dose rates distributions over the core, through the pressure vessel and the biological shield. This calculation is important for the investigation of radiation shielding materials and shield design. Axial and radial cross-sectional views of MCNP-5 model of Korean 1400 MWe reactor displayed in Figure 1.

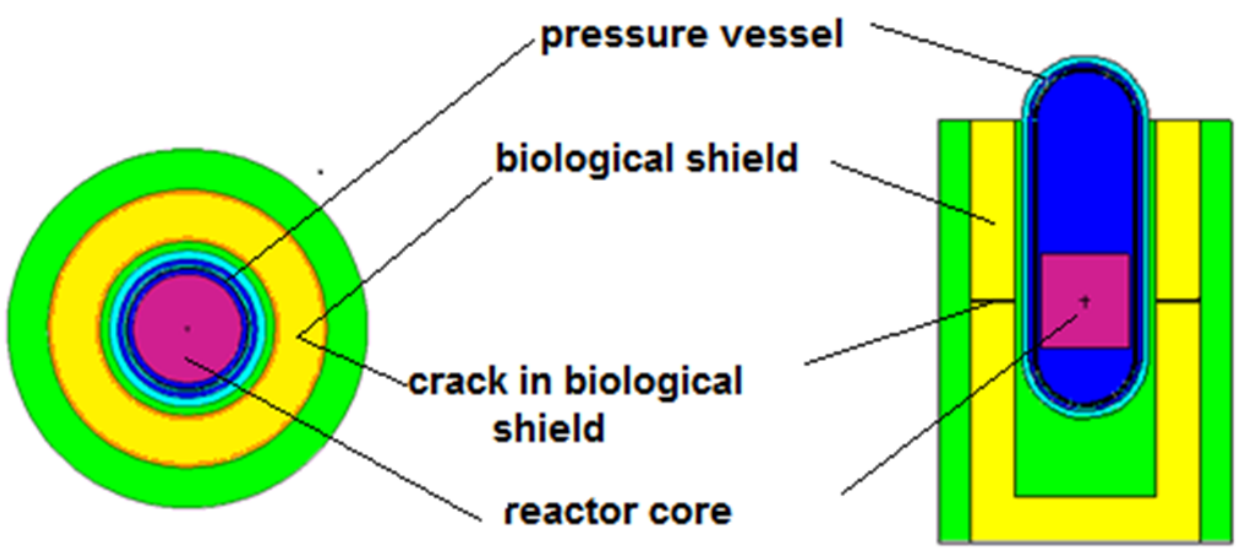

Fig. 1. axial and radial cross-sectional views of MCNP-5 reactor model

The simulation code is running using analytical methods beginning from the source term until the outer surface of the biological shield. To perform neutrons and gamma-ray calculations, first, the code was run in NP mode then followed by P mode. In the first mode neutron-induced gamma-ray tallies while pure photon results could be deduced from the second mode [7].

In this model, the investigated radiation shielding samples were used to calculate neutron and gamma-ray fluxes and dose rates distributions through the reactor core, pressure vessel and biological shield. Different composites such as natural fiber-plastic (FP), fiber-plastic-lead $(\mathrm{FPPb})$, cement fiber $(\mathrm{CF})$ and cement- fiber- magnetite (CFM) with thickness $5 \mathrm{~mm}$ and energy range from 0.015 to $20 \mathrm{MeV}$ have been used. Tally F5 point source was used to obtain the neutron and gamma-ray fluxes and dose rates for different fibers composites at different distances of shield thickness. All simulations were performed with $10^{10} \mathrm{NP}$ and $10^{9} \mathrm{P}$ histories. Also, all the tally results have been passed all statistical checks and they had relative errors of less than $5 \%$. 


\section{Results and discussions}

\section{Mass Attenuation Coefficient $\left(\boldsymbol{\mu}_{\mathrm{m}}\right)$}

The Win X-Com program was used to calculate the $\mu_{\mathrm{m}}\left(\mathrm{cm}^{2} / \mathrm{g}\right)$ for the gamma-ray source. Figure 2 shows the $\mu_{\mathrm{m}}$ of the investigated fiber composites shields, FPPb, CFM, CF and FP at a range of gamma-ray energies from 0.15 to $20 \mathrm{MeV}$. Displayed curves have the same shape for all four samples. From this Fig. it can be observed that the $\mu_{\mathrm{m}}$ value for all samples largely decreases with the increase of photon energy, where are closed at low energy up to $8 \mathrm{MeV}$ then it smoothly decreases with the photon energy increasing till $20 \mathrm{MeV}$. For low, intermediate, and high-energy photons, the fundamental photon interaction process of the photoelectric effect, Compton scattering, and pair production can be used to explain this variation in $\mu_{\mathrm{m}}$, varying by the atomic number of elements of compositions. Additionally, at low photon energy, photoelectric interaction is dominant and is the reason for mass attenuation coefficient reduction while at high energy Compton scattering and pair production are dominant [26]. It is noticed that $\mu_{\mathrm{m}}$ values of $\mathrm{FPPb}$ composite are much greater than those for other samples. This is due to the effect of lead oxide $(\mathrm{PbO})$ addition on $\mathrm{FPPb}$, then CFM and CF which are approximately the same value, while FP has the lowest value. We can conclude that FPPb sample has the best attenuator for gammaray, while, FP has the poorest sample.

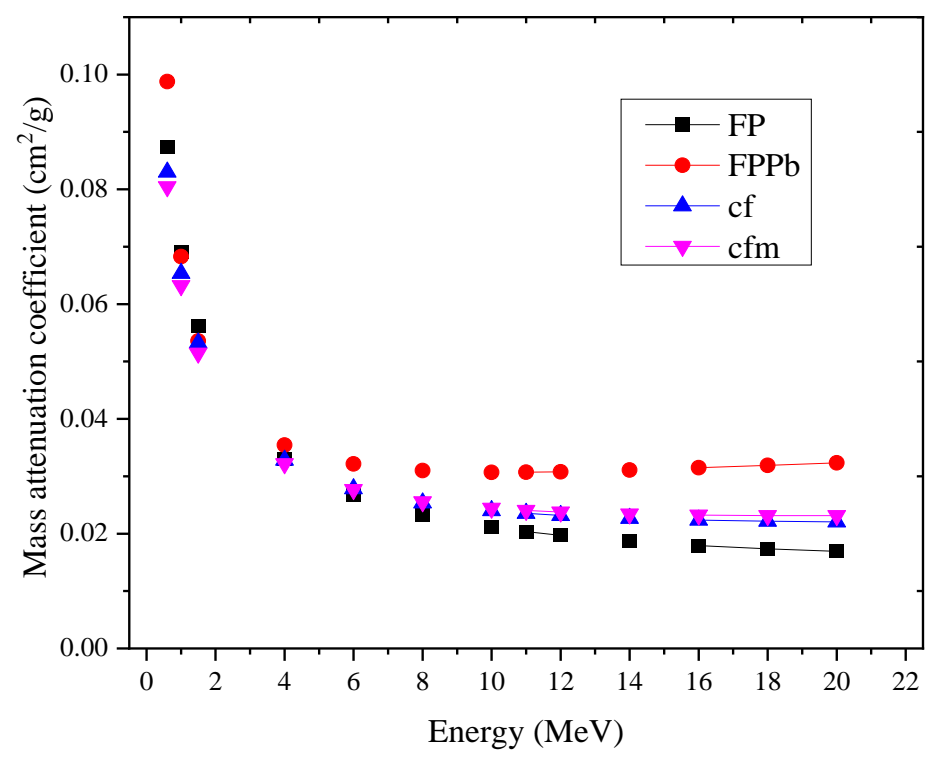

Fig. 2. Mass attenuation coefficient for studied samples at energy range from 0.15 to $20 \mathrm{MeV}$

Comparison of mass attenuation coefficient $\mu_{\mathrm{m}}$ with MCNP-5 and X-Com for composite samples were illustrated in Table 2 . In this table, the value of $\mu_{\mathrm{m}}$ was decreased with the energy increase. It is clear that $\mu_{\mathrm{m}}$ for FPPb composite have the highest values and it's the best material shield for gamma-ray, while, FP has the lowest value. We can understand that the $\mu_{\mathrm{m}}$ of the composites in descending order, which is FPPb $>\mathrm{CFM}>\mathrm{CF}>\mathrm{FP}$. The MCNP and Win X-Com values were agreement. 
Table 2. comparative of mass attenuation coefficients of composite samples with X-Com and $\mathrm{MCNP}$ at Energy range $0.15 \mathrm{MeV}$ to $20 \mathrm{MeV}$

\begin{tabular}{ccccl}
\hline $\begin{array}{c}\text { Energy } \\
(\mathbf{M e V})\end{array}$ & $\begin{array}{c}\text { FP } \\
\text { X-Com MCNP }\end{array}$ & $\begin{array}{c}\text { Mass attenuation coefficient }\left(\boldsymbol{\mu}_{\mathrm{m}}\right) \\
\text { Fb pb } \\
\text { X-Com MCNP }\end{array}$ & $\begin{array}{c}\text { CF } \\
\text { X-Com MCNP }\end{array}$ & $\begin{array}{l}\text { CFM } \\
\text { X-Com MCNP }\end{array}$ \\
\hline 0.15 & $0.1450-0.1441$ & $0.7660-0.7658$ & $0.1450-0.1452$ & $0.1500-0.1505$ \\
0.50 & $0.0944-0.0940$ & $0.1410-0.1415$ & $0.0893-0.0890$ & $0.0865-0.0860$ \\
0.66 & $0.0873-0.0861$ & $0.0959-0.0952$ & $0.0826-0.0824$ & $0.0799-0.0790$ \\
1.12 & $0.0683-0.0682$ & $0.0663-0.0660$ & $0.0645-0.0650$ & $0.0623-0.0629$ \\
1.33 & $0.0617-0.0610$ & $0.0587-0.0590$ & $0.0583-0.0582$ & $0.0563-0.0560$ \\
5 & $0.0293-0.0288$ & $0.0333-0.0338$ & $0.0298-0.0295$ & $0.0295-0.0290$ \\
8 & $0.0233-0.0235$ & $0.0310-0.0316$ & $0.0254-0.0250$ & $0.0255-0.0253$ \\
10 & $0.0212-0.0214$ & $0.0307-0.0312$ & $0.0240-0.0242$ & $0.0244-0.0248$ \\
12 & $0.0197-0.0192$ & $0.0308-0.0311$ & $0.0232-0.0235$ & $0.0238-0.0240$ \\
15 & $0.0183-0.0188$ & $0.0313-0.0315$ & $0.0225-0.0223$ & $0.0233-0.0238$ \\
18 & $0.0174-0.0178$ & $0.0319-0.0318$ & $0.0222-0.0220$ & $0.0232-0.0235$ \\
20 & $0.0169-0.0172$ & $0.0323-0.0320$ & $0.0221-0.0198$ & $0.0231-0.0232$ \\
\hline
\end{tabular}

\section{Cracking in the Biological Shield Model}

Comparison of the total dose rate through the biological shield model with crack and without crack is illustrated in Figure 3. This figure shows the relation between biological shield thickness and total dose rate. From this figure it can be noticed that due to the effect of the crack in the biological shield the values of total dose rate are higher than without crack especially at the beginning of the biological shield while the values are closer at the end of the biological shield.

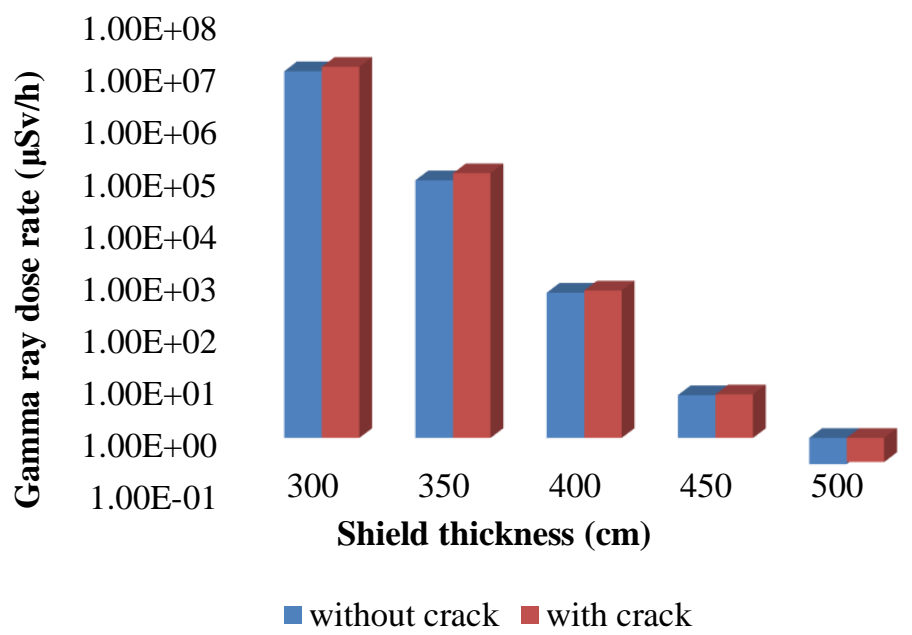

Fig. 3. Dose rate distribution through the biological shield with crack and without crack

\section{Flux and Dose Rate for Neutrons and Gamma Rays}

The calculated flux and dose rate of neutrons, gamma-rays and total (neutrons+ gammarays) dose rate distribution in the simulation model through the crack in the biological shield for different fiber composites samples with thickness $5 \mathrm{~mm}$ in the radial direction inside the reactor core and through the shieling layers are shown in Figure 4 (a-e).

Figure 4-a presents the neutron flux distribution through the reactor core and different distances in the radial direction. The attenuation relation represented in this figure showed that 
the neutron flux intensity decreases with the shield thickness increasing. Also, the rate of depression in the flux is quite high at the first layer of the biological shield for all fiber composites.

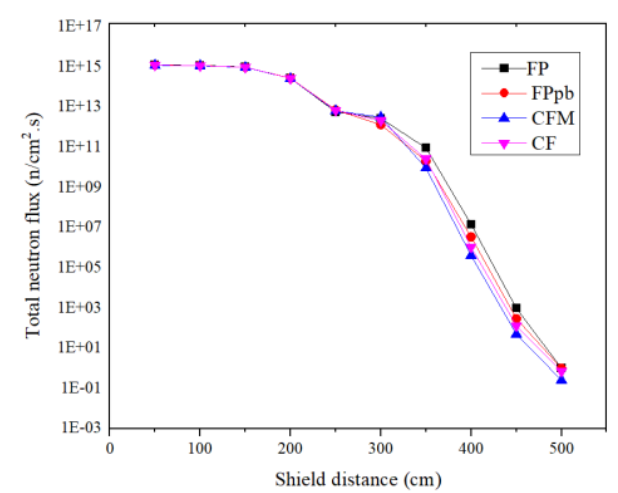

a)

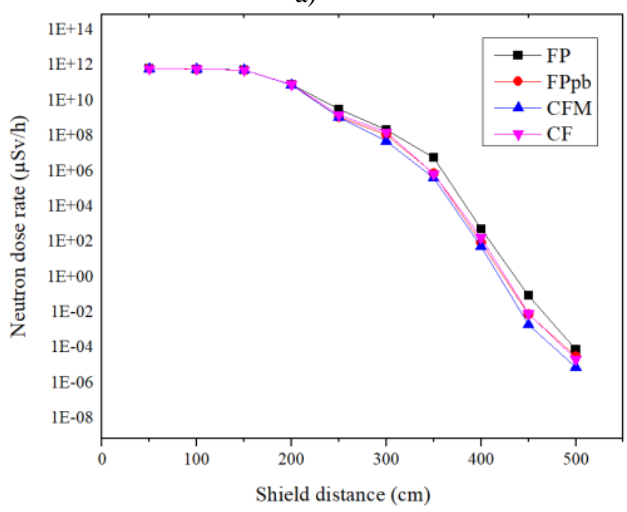

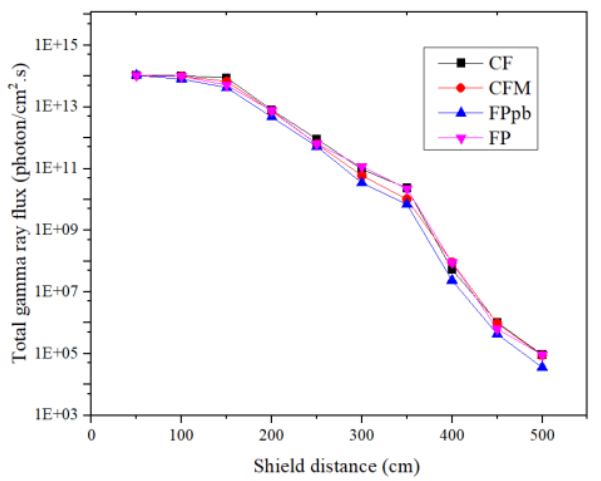

b)

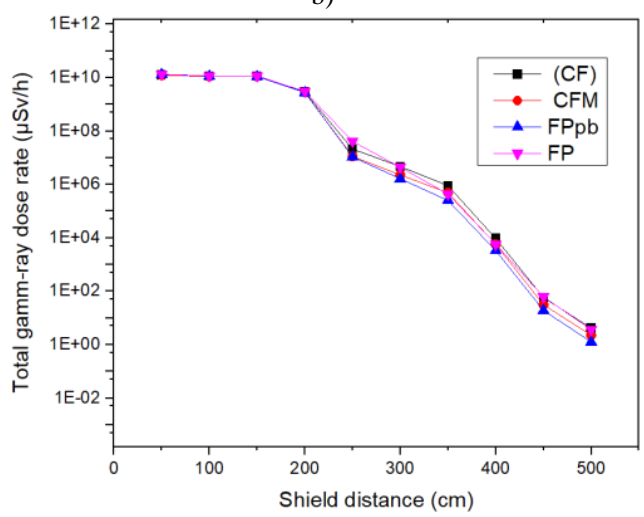

d)

c)

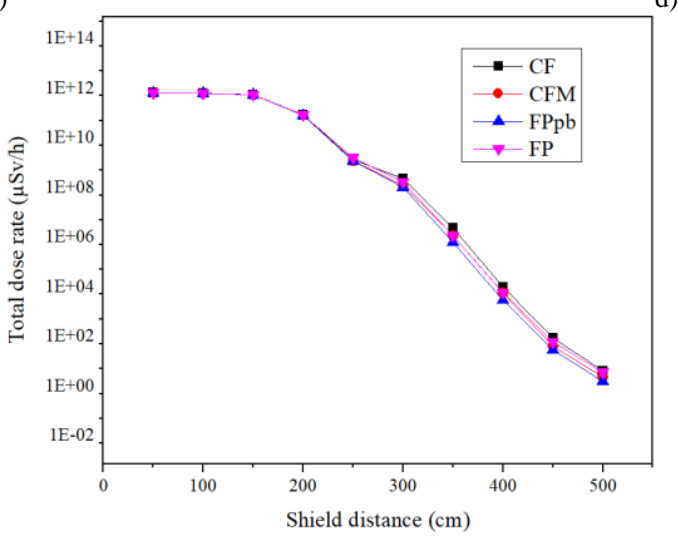

e)

Fig. 4. Total dose rate distribution through the nuclear reactor for different fiber composites: a) Neutron flux distribution; b) Total gamma-ray flux distribution; c) Neutron dose rate distribution; d) Total gamma-ray dose rate distribution; e) Total dose rate $(\mathrm{N}+\mathrm{G})$ distribution 
The maximum neutron flux is inside the reactor core then, it decreases through the thermal shield, this is due to the water thermal shield being an excellent neutron attenuator because of its large hydrogen content. Then it continues decreasing sharply through the pressure vessel and the biological shield this is due to the attenuation and absorption of neutrons through the biological shield. It can also be noticed that CFM composite has a minimum value of neutron flux due it contains magnetite $\left(\mathrm{Fe}_{3} \mathrm{O}_{4}\right)$ and Boron carbide $\left(\mathrm{B}_{4} \mathrm{C}\right)$ which has a high atomic number, while the maximum value at FP composite. The presented attenuation relation is given in this Fig. also shows that CFM is the best attenuator and FP is the poorest attenuator.

Figure 4-b shows the total gamma-ray flux distribution through the different distances of the shield. The max. value of total gamma flux is inside the reactor core while the min. value at the surface of the biological shield. From this Fig. it can be noticed that the FPPb has a minimum value of gamma-ray flux this due to it contains the lead which has a high atomic number also, the impact of lead oxide $(\mathrm{PbO})$ on gamma-ray attenuation is substantial while, the max. value at $\mathrm{CF}$ composite.

Figure 4-c illustrates the variation of neutron dose rate with the distance of shield. From this Fig. it can be concluded that the neutron dose rate values for all fiber composites are nearly constant inside the reactor core then it decreases sharply through different layers of the shield and the minimum value at the outer surface of the biological shield. CFM composite has the min. value because the characteristics of the CFM composite were significantly improved by adding magnetite and boron carbide, while FP is the max. value.

Figure 4-d presents the total gamma-ray dose rates distribution through the shielding layers in a radial direction. The dose rate decreases through stainless steel pressure vessel and concrete biological shield are due to their good attenuation and absorption property for photon shieling. From this Fig., for the fiber composites used in the crack of biological shield the values of gamma-ray dose rate is decreasing and the min. value for FPPb composite, while the max. value at $\mathrm{CF}$ composite.

Figure 4-e shows the total dose rate $(\mathrm{N}+\mathrm{G})$ for different shielding layers and the outer surface of the biological shield. The attenuation relation represented in this Fig. displays that the total dose rate values decrease with the shield distance increases. It can also be noticed that the $\mathrm{FPPb}$ composite has a minimum value then CFM, while, the max. value at CF sample. The presented attenuation relation is given in this figure also showed that $\mathrm{FPPb}$ composite is the best attenuator than $\mathrm{CFM}$, while, $\mathrm{CF}$ is the poorest attenuator.

\section{Radiation Protection Efficiency (RPE\%)}

The values of RPE\% of the investigated fiber composites shields for neutrons and gamma rays with different energy at the surface of the biological shield with crack and after using four fiber composite materials with $5 \mathrm{~mm}$ thickness as a filler for cracking of the nuclear reactor biological shield have been calculated using Equation 2 and presented in Figure 5.

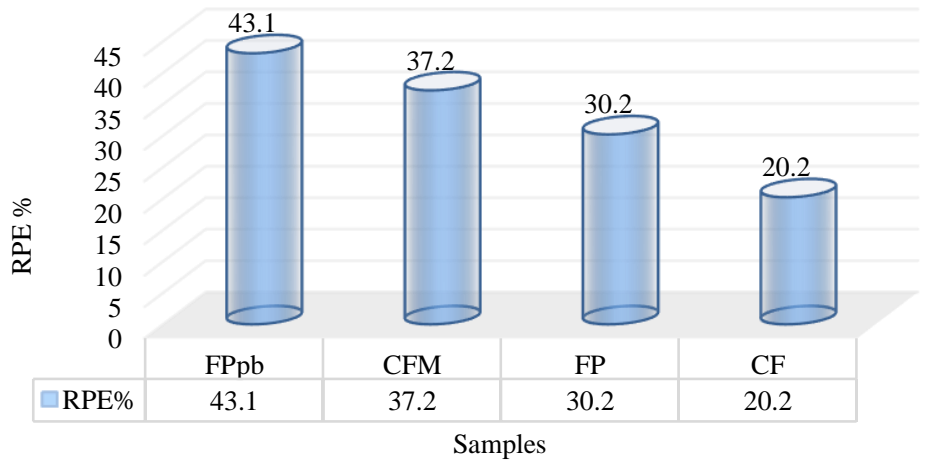

Fig. 5. The calculated Radiation protection efficiency for studied fiber composites shields 
From this figure, it can be noticed that the max. value of RPE \% for FPPb is (43.1\%), then CFM (37.2\%), Fp (30.2\%) and CF (20.2\%). The RPE\% results are completely in agreement with all the other results, Where the FPPb sample has the highest RPE\%, while CF has the lowest value.

\section{Conclusions}

The obtained calculated results for natural fiber composites of FP, FPPb, CFM and CF are given and discussed before. The following conclusions can be derived:

- In the nuclear reactor biological shield model, due to crack, the neutron and gamma-ray total dose rates increase and the values are higher than without crack.

- Mass attenuation coefficients $\mu_{\mathrm{m}}$ of the studied samples are decreasing with the photon energy increases. $\mu_{\mathrm{m}}$ decrease sharply from $10 \mathrm{keV}$ to $0.8 \mathrm{MeV}$, while, it smoothly decreases with low sensitivity to the photon energy from $10 \mathrm{keV}$ to $0.8 \mathrm{MeV}$. FPPb sample has higher $\mu_{\mathrm{m}}$, than CFM, CF and FP.

- Flux and dose rate values for both neutron and gamma-rays are decreasing with the shield distance increase. FPPb is the best material for gamma-ray because it contains lead which has a high atomic number. Also, CFM has the best material shield for neutron and also gammaray, the characteristics of the CFM composite were significantly improved by adding magnetite and boron carbide.

- Max. value of RPE \% for FPPb is $(43.1 \%)$, then CFM (37.2\%), Fp (30.2\%) and CF (20.2\%). FPPb sample has the highest RPE\%, while CF has the lowest value. The order of choosing fiber composites as additives to the biological shield crack as a filler to be used as a shielding material is $\mathrm{FPPb}>\mathrm{CFM}>\mathrm{FP}>\mathrm{CF}$.

The current results show that these composites have high shielding and radiation attenuation capabilities, especially when heavy metals or minerals are added. Natural fiber is a recyclable, eco-friendly and renewable raw material. From obtained results indicate that the new materials can be applied as a filler for cracks in the biological shields for nuclear power reactors.

\section{References}

[1] P.M. Bruck, T.C. Esselman, B.M. Elaidi, J.J. Wall, E.L. Wong, Structural Assessment of Radiation Damage In Light Water Power Reactor Concrete Biological Shield Walls, Nuclear Engineering And Design, 2019, 350, pp 9-20.

[2] Nesreen R. Abd Elwahab, Nadia Helal, Tarek Mohamed, Fayez Shahin, Fadel M. Ali, New Shielding Composite Paste for Mixed Fields of Fast Neutrons And Gamma Rays, Materials Chemistry and Physics, 2019, 233, pp. 249-253.

[3] Mehrnejad R, Improving Neutron Shielding Capacities of Datolite and Galena by Boron Carbide Additive for Nuclear Reactor Biological Shielding, J Phys Chem Biophys, 2009, 9(2), p. 278.

[4] K.A. Mahmoud, E. Lacomme, M.I. Sayyed, O.F. Ozpolat, O.L. Tashlykov, Investigation of the Gamma Ray Shielding Properties for Polyvinyl Chloride Reinforced with Chalcocite and Hematite Minerals, Heliyon, 2020, 6, e03560.

[5] K.A. Mahmoud, O.L. Tashlykov, A.F. El Wakil, I.E. El Aassy, Aggregates Grain Size and Press Rate Dependence of The Shielding Parameters for Some Concretes, Prog. Nucl. Energy, 2020, 118, p. 103092.

[6] A.M. Abu El-Soad, M.I. Sayyed, K.A. Mahmoud, E. S, akar, E.G. Kovaleva, Simulation Studies for Gamma Ray Shielding Properties of Halloysite Nanotubes Using MCNP-5 Code, Appl. Radiat. Isot., 2019, p. 108882. 
[7] A. T. Gheith, M. A. El-Sarraf, I. E. Hasan, N. L. Helal, R. A. Rizk, Amal A. El-Sawy, A. ElSayed Abdo, Assessment of A Polymeric Composite as A Radiation Attenuator and A Restoration Mortar for Cracking in Biological Shields, Nuclear Physics and Atomic Energy, ISSN 1818-331X, 2020, 21(4).

[8] El- sarraf, M. A., El- Sayed Abdo, A., 2013b. Influence of Magnetite and Boron Carbide on Radiation Attenuation of Cement- Fiber, Composite. Ann. Nucl. Energy 30, 391-403.

[9] Alparslan Erol, Isa Pocan, Emre Yanbay, Onur Alp Ersöz, Fatma Yurt Lambrecht, Radiation Shielding of Polymer Composite Materials with Wolfram Carbide and Boron Carbide http://www.rpe.org.in, accessed on June 9, 2020.

[10] Harshbab Singh, Rishi Gupta, Influence Of Cellulose Fiber Addition On Self-Healing And Water Permeability Of Concrete Case Studies, Construction Materials, 2020, 12, e00324.

[11] E. Cailleux, V. Pollet, Investigations on the Development of Self-Healing Properties, Protective Coatings for Concrete and Repair Mortars, 2019.

[12] S. Kim, D.Y. Yoo, M.J. Kim, N. Banthia, Self-Healing Capability Of Ultra-HighPerformance Fiber-Reinforced Concrete After Exposure To Cryogenic Temperature, Cem. Concr. Compos., 2009, 104(1), p. 11.

[13] S. Kim, M.J. Kim, H. Yoon, D.Y. Yoo, Effect of Cryogenic Temperature on The Flexural and Cracking Behaviors of Ultra-High-Performance Fiber-Reinforced Concrete, Cryogenics, 2018, 93, pp. 75-78.

[14] A. El-Sayed Abdo, M.A.M. Ali, M.R. Ismail, Natural Fiber High-Density Polyethylene and Lead Oxide Composites for Radiation Shielding, Radiation Physics and Chemistry, 2003, 66, pp. 185-195.

[15] A. El-Sayed Abdo, M.A.M. Ali, M.R. Ismail, Influence of Magnetite and Boron Carbide On Radiation Attenuation Of Cement-Fiber/Composite, Annals of Nuclear Energy, 2003, 30, pp. 391-403.

[16] Kansouh, W.A., El-Sayed Abdo, A., Megahid, R.M., 2001. Radiation Shielding Properties of Dolomite and Ilmenite Concretes. In: 4th Conference and Workshop on Cyclotrones and Applications, 17-21 Feb. 2001, Cairo, Egypt.

[17] El-Sayed Abdo, A., Megahid, R.M., Homogeneous and Multilayered Shields For Neutrons And Gamma-Rays. Jpn. J. Appl. Phys., Part 1, 2001, 40 (4A), pp. 2460-2464.

[18] A.M. Madbouly, Amal A. El- Sawy. Optimization of Concrete Mix with Tungsten Composite Materials as a Gamma-Ray Radiation Shielding. International Journal of Scientific \& Engineering Research, 2021, 12(6).

[19] M. Almatari, Shams A.M. Issa, M.G. Dong, M.I. Sayyed, R. Ayad, Comparison between MCNP5, Geant4 and Experimental Data for Gamma Rays Attenuation Of Pbo-Bao-B2O3 Glasses, Heliyon, 2009, 5, e02364.

[20] H.O. Tekin, M.I. Syyed, E.E. Altunsoy, T. Manici, Shielding Properties and Effects of Wo3 and Pbo on Mass Attenuation Coefficients by Using MCNPX Code, Digest J. Nanomater. Biostruct., 2017, 12, pp. 861-867.

[21] A. A. El-Sawy, Development of Nuclear Power Reactor Shielding Using Two Different Types of Heavy Concrete, Arab Journal of Nuclear Sciences and Applications, 2017, 50(3), pp. 151-158.

[22] Piotrowski Tomasz, Tefelski Dariusz B., Sokołowska Joanna J., Mazgaj Michał1, Skubalski Janusz and Żak Andrzej, Polymers in Concrete - The Shielding Against Neutron Radiation, Advanced Materials Research, 2015, 1129, pp 131-138. 
[23] B Aygün, Neutron and Gamma Radiation Shielding Properties Of High-Temperature Resistant Heavy Concretes Including Chromite And Wolframite, Journal Of Radiation Research And Applied Sciences 2019, 12(1), pp. 352-359.

[24] Abdelghany A. El Abd and Ashraf S. Elkady, A Method for Simultaneous Determination of Effective Removal Cross-section for Fast Neutrons and Mass Absorption Coefficient for Gamma Rays, SOJ Mater Sci Eng. 2(2), pp. 1-6, doi:10.15226/sojmse.2014.00113.

[25] Kyo Min Lee and Sang Ho Kang, Radiological Characterization of Decommissioning Wastes from Korean 1400 MWe PWR: Activated Reactor Internals, Engineering \& Construction Company Inc., Buenos Aires, 12 al 17 de Abril, 2015 Sociedad Argentina De Radioprotección.

[26] Hassan H.E., BadranH.M., Aydarous A., Sharshar T., Studying the Effect Of Nano Lead Compounds Additives On The Concrete Shielding Properties for $\gamma$-Rays. Nucl. Instru. Meth. Phys. Rese. B, 2015, 360, pp. 81-89.

Received: October 19, 2021

Accepted: November 30, 2021 